\title{
Participatory Education As Empowerment: A Case Study On Loss, Grief And Empowerment
}

\author{
Keith Miller* \\ School of Social and Policy Studies, Flinders University, GPO Box 2100, Adelaide, South \\ Australia, 5001
}

Article history

Received:

01.03.2015

Received in revised form: 20.06.2015

Accepted:

23.06.2015

Key words:

Participant education, empowerment, Seasons for Healing, community, insiders, outsiders
As Freire indicated, for education to be successful, it needs to be participatory where both student and teacher recognise the educational capacity within each other. In order for education to be participatory, there needs to be empowerment of the recipients of the education. This is particularly true when the education is delivered cross-culturally and in a community setting. A community can be defined as a group of people who live and work cooperatively together. Education in a community setting empowers both individuals but also the community as a whole. Delivery of education to a community comprises both insiders and outsiders. Insiders are the community members who know intuitively how the community operates. Outsiders do not know experientially how a community functions. When outsiders bring expertise into a community, it is the insiders who can adapt that expertise and make it relevant to that community. Seasons for Healing was an educational loss and grief program implemented in Aboriginal communities in South Australia. Incorporating an interpretive, yet also critical and reflexive ethnography, expertise from outsiders combined with experiential insight from insiders enabled people from Aboriginal communities to be empowered through participant education. As people within communities participated in their own education through the Seasons for Healing Program, an awareness of their own empowerment developed.

\section{Introduction}

What does it mean to belong to a community, to be an insider, to intuitively know how one should think and behave without instruction? What does it mean to be an outsider, to never fully be able to appreciate the perspective with which an insider views and understands their community? In this article, I wish to think through the process of becoming involved in the education of others in a participatory sense. And the emphasis I want to bring is what I believe to be the crucial importance of empowering those within a community to become involved in their own education. I will use my experiences and learnings from involvement in

\footnotetext{
"Correspondence: keith.miller@flinders.edu.au
} 
Australian Aboriginal communities, in particular when introducing a change, loss and grief educational program into these communities, to consider participatory education as empowerment.

For me, in engaging with a community from another culture, it is important to use an ethnographic approach, which 'pose(s) questions at the margins between two cultures. (It) necessarily decode(s) one culture while re-coding it for another' (van Maanen, 1988, as cited in Alexander, 2005, p.418; Atkinson \& Hammersley, 2007; Foley \& Valenzuela, 2005). More specifically, the use of a critical interpretivist framework with self as learner (Alexander, 2005; Clark, 2000, as cited in Gair, 2008, p.223; Crotty, 1998; Denzin \& Lincoln, 2011) will give opportunity to be reflexive in my understanding and interpretation of the one culture as interpreted by another (Kovach, 2009). What are 'the methods of knowledge production' within cultures and how do 'particular knowledges achieve legitimacy and authority at the expense of other knowledge' (Nakata, 2007, p.195)? Yet, added to this are the benefits of a critical and yet reflexive ethnographic approach, which 'takes us beneath surface appearances, disrupts the status quo, and unsettles both neutrality and taken-for-granted assumptions by bringing to light underlying and obscure operations of power and control' (Madison, 2005, p.5). So my approach has incorporated an interpretive, yet also critical and reflexive ethnography.

For me, the process of engaging with a community involves personal education, experiencing life and culture from a different perspective, and gaining insight via a different paradigm, in order to then become involved in participatory education. As a white, middle-aged, Anglomale, the lens through which I see the world is western. Over the last few years, however, I have come to question the objectification and rationalisation of knowledge and come to realise that there is inevitably a sense of subjectivity with which we approach the reality around us (Miller, 2014). Now, I need to add to this and recognise that it is still presumptuous of me to approach reality as though my perspective is the most important reality. I will use my involvement in a particular project as the vehicle for considering the change in my personal understanding. The project in which I have become involved has an educational perspective, it has been participatory by involving participants from within and outside of the community and the project has endeavoured to empower those within the community.

\section{The Project}

'The Seasons for Growth Adult Program was specifically developed to address the needs of adults to understand and manage change, loss and grief in their lives' (Good Grief, 2011, p.7). It has been operating as an educational program in Australia since 2005 and trains individuals and groups to better understand and manage these issues in their personal experience. The Aboriginal and Torres Strait Islander Healing Foundation recognised the potential for such a program in Indigenous Aboriginal communities (2011). This Foundation provided funding to Aboriginal Family Support Services in South Australia and to Good Grief Ltd, a Catholic, non-government organisation focused on educational and wellbeing services based in Sydney (Good Grief, 2013), to develop an equivalent program for Aboriginal communities. This new program was called Seasons for Healing.

The Seasons for Healing Program was an educational loss and grief program, adapted from the Seasons for Growth Program, 'to support Aboriginal and Torres Strait Islander adults' (Good Grief, 2012, p.2). It was based on Worden's four tasks of grief (Worden, 2009, pp.3953) and was structured around the four seasons of autumn, winter, spring and summer. These 
four tasks of grief were: to accept the reality of the loss (envisaged as the autumn of one's experience), to process the pain of grief (winter), to adjust to a world without the deceased (spring), and to find an enduring connection with the deceased in the midst of embarking on a new life (summer). The four seasons depicted in a concrete way what was happening for an individual in each task of grief.

Two members of a community were selected and trained as 'companions', their role being to facilitate a small group of between four and seven people within that community. These cocompanions led the group through a program of four sessions, each session lasting approximately two and a half hours. Through participating in a range of activities, companions enabled group members to appreciate the impact of change, loss and grief on their lives and to gain the language to better articulate experiences of change, loss and grief. Over a period of four sessions, which corresponded to the four seasons, participants were able to 'acknowledge the reality of their loss', 'explore the range of feelings and reactions that come with loss', 'adjust to their changed circumstances' and 'explore the choices that enable participants to let go and move forward' (Good Grief, 2012, pp. 24, 46, 68, 88). Each session incorporated time for discussion, listening, contemplation, activities, and opportunities for writing and self-expression.

I was invited to be part of an Advisory Group of nine people, made up of senior staff from Aboriginal Family Support Services (AFSS) and Good Grief Ltd, to adapt the Seasons for Growth Program into an Aboriginal context as Seasons for Healing. This Advisory Group comprised both Indigenous and non-Indigenous members and met for nine months prior to rolling out the Program in communities around South Australia.

AFSS works within a number of Aboriginal communities in metropolitan Adelaide and in regional, rural and remote communities in South Australia. In order to deliver this Program, AFSS chose staff members from a range of communities to be trained as companions. These companions were trained in several two day workshops between 2012 and 2013 to deliver the Seasons for Healing Program. The companions then went back to their communities, invited a small group of community members who would be willing to participate and then delivered the Program as a two day workshop, and these workshops occurred between 2012 and 2014 in a range of communities. There were 61 companions and a number of community members (for the sake of anonymity, no further details will be provided on community members) in total from 13 communities who participated in Seasons for Healing Programs across metropolitan and rural South Australia. One of my roles was to go to each of the communities following the delivery of the Program and evaluate its effectiveness. Companions were asked to respond by means of a written questionnaire to indicate the effectiveness of the Program from their perspective. I also spoke with the two companions at each location to gain some further understanding. Small-group focus groups (of between two and five people) were also used to capture further information about the implementation of the Program from the community members who participated in the Program. Ethics approval was gained from the Aboriginal Health Research Ethics Committee, Aboriginal Health Council of South Australia, and the Flinders University Social and Behavioural Research Ethics Committee.

An educational program was thus developed utilising the expertise and insight of both Aboriginal and non-Aboriginal people in the preparation phase. This program was then delivered into a number of Aboriginal communities. So experts from both within the communities and from outside of the communities participated in developing and delivering this educational endeavour and, in the process, empowered those within the communities. 


\section{Community}

A community can be defined as a group of people who live and work cooperatively together. Those who provide educational services to members of this community may be designated as insiders who have an intimate and ongoing connection to other members, or they may be outsiders and so not intimately involved as part of that community (Gunaratnam, 2003). There are both positive and negative aspects to these designations. If a person is an insider, then they are more deeply and personally affected by decisions made within their community, they are there for the long-term, often all hours of the day or night and they are unable to escape from the demands of the community. As Tuhiwai-Smith states, they 'have to live with the consequences of their processes on a day-to-day basis for evermore' (1999, p.137). If a person is an outsider, they can escape these ongoing demands but they also do not have an experiential knowledge as to how decisions will affect the community.

My proposal in this article is that it is important that insiders have significant input into the decisions which affect both their community and themselves at a personal level. It is important that insiders are empowered to be part of any educational process which occurs within a community. It is also important that insiders have access to the expertise which outsiders can bring, but this expertise needs to be offered in a respectful manner. Insiders need to have the final say in terms of the application of outside expertise which impacts on the lives of those personally affected.

\section{Participatory Education}

Participant involvement in education is an important concept, even though different designations have been and continue to be used to convey the concept. In his classical text, Pedagogy of the Oppressed, Paulo Freire discussed authentic education (as he referred to it). He surmised that, 'Authentic education is not carried on by A for B or by A about B, but rather A with B, mediated by the world' (1970, p.66, italics in original). This is participatory education where both teacher and student recognise the educational capacity within each other. The subsidiary clause in this quotation is also significant, 'mediated by the world'. Freire's world was one of oppression by the powerful over the oppressed in what was then the deeply divided society of Brazil. The life context in which people found themselves could not be denied. Educators needed to take account of 'the men-in-a-situation towards whom their programme was ostensibly directed' (1970, p.66, italics in original). Participatory education needs to recognise and take advantage of the cultural context of the participants. Unless the context is considered, the 'men-in-a-situation' will be unable to see the relevance of the education in which the educators invite them to participate.

Freire elaborated on these thoughts in a reflective piece in 1974 when he commented that, 'The method (of education) was to be based on dialogue, which is a horizontal relationship between persons' (2008, p.40). He differentiated this from 'anti-dialogue' where 'the relationship of empathy is broken; the teacher is seen as powerful' and 'does not communicate but issues communiques' (2008, p.41). Swantz and Vainio-Mattila remark in a similar vein that, 'people do not have to passively accept what is thrust upon them: participatory inquiry...offers one way to escape from the prevailing state...of merely being acted upon' (1988, p.127). So the emphasis in participatory education is that of equal participation in the learning process.

Hence, Freire advocates against a purely 'top-down' approach to education (1970, p.67) with the inference that those in leadership cannot merely impose their views on others. Ife 
contrasts a 'top-down' and bottom-up' approach to community development (2010, p.17). Using Ife's terminology, his contention is that a 'top-down' approach is ineffective without a concomitant 'bottom-up' approach and that both of these approaches are important and can be combined for the most effective involvement in a community. Those involved in developing and delivering the Seasons for Healing Program attempted to incorporate the 'top-down' and 'bottom-up' approach of combining the expertise of Indigenous and non-Indigenous specialists and educators from outside of the communities with the expertise of participants from within the communities.

For me, participatory education and empowerment are inextricably linked. Wallerstein and Bernstein (1994, p.142) define community empowerment as 'a social-action process in which individuals and groups act to gain mastery over their lives in the context of changing their social and political environment'. Wallerstein and Bernstein (1994) consider the views of Shor and Freire, who 'advocate a participatory education process in which people are not objects or recipients of political and educational projects, but actors in history, able to name their problems and their solutions to transform themselves in the process of changing oppressive circumstances' (1987, p.109). In engaging in participatory education, one is also and inevitably empowering those who are being educated. This is emphasised by McQuiston, Choi-Hevel and Clawson who state that 'collaborative inquiry focuses on empowering participants... and building community capacity' (2001, p.276). In this way, it gives community members a voice and a role as decision makers in program development and ensures that the cultural and community context are included within the program. As Reason states, 'the emphasis in participatory research is in establishing a dialogue between research workers and grass-roots people with whom they work, in order to discover and realize the practical and cultural needs of those people' (1988, p.2). This mutually beneficial and empowering approach is equally true with participatory education.

\section{What is empowerment?}

This world divided into compartments, this world cut in two is inhabited by two different species... When you examine at close quarters the colonial context, it is evident that what parcels out the world is to begin with the fact of belonging to or not belonging to a given race, a given species (Fanon, 1967, p. 30).

Writing in 1967 from Algeria, a country colonized by France, Frantz Fanon recognized the enormous gulf between dominant and subservient cultures during that epoch. He acknowledged that accident of birth determined whether a person belonged or did not belong to 'a given race', whether a person had opportunity in life, and the privileges which resulted from this. Probably even in 1967, the world context was more complex than a duality between dominance and servitude. But this was Fanon's reality.

Educators have traditionally been powerful people of privilege and belonged to 'a given race'. They have belonged to the dominant rather than the subservient culture. Tuhiwai Smith makes a statement about research but the same can equally apply to education: '(Researchers) have the power to distort, to overlook, to make invisible, to exaggerate and to draw conclusions based...on assumptions, hidden value judgements, and often downright misunderstandings' (2012, p.178). So there is a responsibility on the part of both researchers and educators to recognise the power imbalance and consequently to accord a rightful sense of power to research and educational participants. As Tuhiwai Smith also says, these researchers (and educators) are 'in receipt of privileged information' from participants (2012, p.178). Too often, researchers have 'come into Indigenous communities to collect their stories to 
disappear without a word coming back or any benefit returning to the community' (BrydonMiller et al., 2011, p.390). In terms of Indigenous communities, Tuhiwai Smith makes a strong comment: "The way in which research is implicated in the worst excesses of colonialism remains a powerful remembered history for many of the world's colonized peoples' (1999, p.1). 'Education' can be added to this statement along with 'research'. To ensure that empowerment occurs, educators need to approach an Indigenous community with a participatory mindset.

It is important that an educator recognises themselves as either an 'outsider' or an 'insider' when engaging in participatory education in an Indigenous context. What this means is that an educator from outside of the community genuinely hears what the community is saying and the different perspectives amongst community members (Pelias, 2011). When an educator works with a group of people from a different cultural or sub-cultural background, including an Indigenous background, the educator should not assume knowledge and should recognise the power imbalance (Martin, 2003). The educator should understand her/himself as the one willing to learn, the one who shows humility and accords deference to those receiving the education. There should be a genuine participation in this educative process on the part of all concerned.

So there needs to be community ownership of the change process. The community itself needs to be involved in how and when the change will be delivered. This will mean that an introduced educational program becomes their program, they identify with it and they recognise its value and importance to their community (Safe Living in Aboriginal Communities Project, 2002). Leadership means empowering people within a community to engender change from within.

In the Seasons for Healing project, my approach was as a learner, and I attempted to treat with respect those with whom I engaged. Indigenous members of the Advisory Group were involved in adapting the project into an Aboriginal context, in choosing the participants and in delivering the Program. As an 'outsider', I attempted to ensure that my interests were subservient to those of the Indigenous people involved in the Program. The participants were given opportunity to provide their perspective and ideas. There was a 'walking with' rather than a 'doing for', a 'journeying with' rather than 'imposing an outside expert opinion'. I made it clear that I was not coming with the answers I expected to hear, but I genuinely respected their input and listened carefully to their insights on change, loss and grief. Their responses were to me unexpected at times and often different to what I expected to hear.

\section{Delivery Of The Project}

Through interaction in a group setting, participants shared their views and, by this means, constructed a group understanding of change, loss and grief, as well as how they could interpret and safely express this new understanding. The interaction between participants enabled a richer expression for each participant of the issues which were both discussed verbally and communicated in other ways, such as in listening, contemplation, activities and opportunities for writing and self-expression. The role of the facilitator was that of 'walking with' the participants on their journey of discovery. Hence, realities of all participants were 'socially and experientially based' (Guba and Lincoln, 1994, p.110). 


\section{Engagement In The Project}

Listening to participants describe their understanding and share their experiences was an enriching time for me. Grief holds a significant place in the lives of Aboriginal people. Any form of loss a person experiences can lead to grief, and this was recognised by participants in the focus groups.

- 'In Aboriginal culture, lots of people die. Sometimes we bury one next month, sometimes ten in a month. Grief takes over our whole lives' (B, northern Adelaide).

- 'There are other kinds of loss - identity, land, belongings, where we fit in with all this' (M, southern Adelaide).

I came to recognize that grief is not an unfortunate addition to life, as it is often viewed from a western perspective. For Indigenous people, it is an intimate part of who they are.

The Seasons for Healing Program was recognized as providing a meaningful understanding of loss and how to manage the grief process which inevitably affects people's lives.

- '(The Program) gave me a better understanding of how to deal with grief and loss. You have some tools but extra information is helpful. To do this with people you trust impacts on you' (C, northern Adelaide).

- 'A lot of our mob talk about death, losing someone brings grief, but not just death but about lots of things. Relationships with partner, family, etc. We need education around this stuff' (Sh, southern Adelaide).

Education around loss and grief was seen as valuable because the cultural perspective of coping with these issues has been lost.

The Program provided a means of reflecting on loss and finding new ways of coping.

- 'When I have upset days I can think of (the Program). When I am wrapped up in a doona, thinking of it all because I was taken away from my family' (L, northern Adelaide).

Participants enjoyed sharing their stories and recognising that there can be enriching aspects to sharing the grief and loss which they have experienced in their lives.

- 'It was nothing that I had expected. It was much better. Its positive spin makes you want to participate. I never thought I would be laughing in a grief and loss program. It wasn't what I expected' (S, southern Adelaide).

- 'I am showing you 66 years of my life on this piece of paper' (J, rural South Australia).

'Yarning', or telling a personal story, is an important part of Aboriginal culture. It was recognised as a means of individuals sharing parts of who they are for the benefit of the group. So this was incorporated more fully into the program.

- 'When you are sharing a story - you need more time to yarn. Obviously there are things people want to say... We are story tellers' (P, northern Adelaide).

Several of the groups commented on the need to keep the group together throughout the 
program. This was linked to the recognition of the importance of yarning and the relational nature of engagement.

- 'We chose to remain as a group. Yarning is really good for us' (N, rural South Australia).

And yet, the size of the group needed to remain intimate.

- 'It would have lost its closeness if there were more people. Five is the max' (A, southern Adelaide).

The idea of mentoring was a valuable concept expressed clearly in one group but indicated in a number of other groups. This was an unanticipated benefit of the program which a number of the groups mentioned.

- 'We have different journeys in all our lives...Different ages can learn from each other. We learnt from the oldies and the youngies learnt from us. It gives a balance' (M, southern Adelaide).

- 'Have a mix of older and younger people. The older ones encourage the younger ones across the table, giving a nod forward of the kind you would give as communication without words to say - ok, it's your turn to talk' (K, rural South Australia).

This 'communication without words' within the groups indicated an unspoken understanding and awareness of other participants.

Each group emphasised the importance of ending each session on a positive note. This meant that people who attended only for part of the program could gain something positive from it. It also meant that the spirits of participants were lifted and those who were able to continue with the program were encouraged to return.

- 'The ending needs to be positive otherwise I feel depressed and don't want to come back' (T, rural South Australia).

What was encouraging to me was that participants in the program felt that it accorded with the aims of the Aboriginal and Torres Strait Islander Healing Foundation (2011) in that it strengthened social, spiritual, emotional and physical well-being within their communities and it strengthened cultural identity and pride.

- 'The focus of activities allows people to strengthen their connection to culture, their spiritual, emotional and physical well-being' (M, Port Augusta).

- 'Stronger individuals make stronger communities' (W, Ceduna).

There was a range of responses from participants. As I spent time with the different groups, more and more I started to listen to them. It took time to take away my western cultural mindset and to begin to hear what they were saying, both verbally and from within. I started to see the world from their perspective, to understand what was important to them. Hence, for me, participatory education is a two-way process, as Freire mentions (2008). As people within communities participated in their own education through the Seasons for Healing Program, an awareness of their own empowerment developed. 


\section{Conclusion}

As Freire commented, for education to be successful, it needs to be participatory (1970), where both student and teacher recognise the educational capacity within each other. In order for education to be participatory, there needs to be empowerment of the recipients of the education. This is particularly true when the education is delivered cross-culturally.

A community can be defined as a group of people who live and work cooperatively together. Insiders are the community members who know intuitively how the community operates. Outsiders do not know experientially how a community functions. When outsiders bring expertise into a community, it is the insiders who can adapt that expertise and make it relevant to that community.

Seasons for Healing was an educational loss and grief program implemented in Aboriginal communities in South Australia. Expertise from outsiders combined with experiential insight from insiders enabled people from Aboriginal communities to be empowered through participant education.

\section{References}

Aboriginal and Torres Strait Islander Healing Foundation (2011) Our Healing Our Solutions. Canberra: Aboriginal and Torres Strait Islander Healing Foundation.

Alexander, B. K. (2005) 'Performance Ethnography: The Reenacting and Inciting of Culture', in N. K. Denzin and Y. S. Lincoln (eds) The Sage Handbook of Qualitative Research, 3rd ed, pp. 411-441. Thousand Oaks, CA: Sage Publications.

Atkinson, P. and Hammersley, M. (2007) Ethnography: Principles and practice, 3rd ed. New York: Taylor and Francis.

Brydon-Miller, M., Kral, M., Maguire, P., Noffke, S. and Sabhlok, A. (2011) 'Jazz and the Banyan Tree: Roots and Riffs on Participatory Action Research', in N. K. Denzin and Y. S. Lincoln (eds) The Sage Handbook of Qualitative Research, 4th ed, pp. 387-400. Thousand Oaks, CA: Sage Publications.

Crotty, M. (1998) The Foundations of Social Research: Meaning and Perspective in the Research Process. St Leonards, NSW: Sage Publications.

Denzin, N. K. and Lincoln, Y. S. (2011) 'Introduction: The Discipline and Practice of Qualitative Research', in N. K. Denzin and Y. S. Lincoln (eds) Sage Handbook of Qualitative Research, 4th ed, pp.1-19. Thousand Oaks, CA: Sage Publications.

Fanon, F. (1967) The Wretched of the Earth (C. Farrington, trans). London: Penguin Books. Foley, D. and Valenzuela, A. (2005) 'Critical Ethnography: The Politics of Collaboration', in N. K. Denzin and Y. S. Lincoln (eds) The Sage Handbook of Qualitative Research, 3rd ed, pp.217-234. Thousand Oaks, CA: Sage Publications.

Freire, P. (1970) Pedagogy of the Oppressed, transl. M. B. Ramos. Harmondsworth, UK: Penguin Education.

Freire, P. (2008) Education for Critical Consciousness. London: Continuum.

Gair, S. (2008) 'Missing the "Flight from Responsibility": Tales from a Non-Indigenous Educator Pursuing Spaces for Social Work Education Relevant to Indigenous Australians', in M. Gray, J. Coates and M. Yellow-Bird (eds) Indigenous Social Work Around the World: Towards Culturally Relevant Education and Practice, pp. 219-230. Aldershot, UK: Ashgate Publishing.

Good Grief (2011) Seasons for Growth Adult Program Companion Manual, 3rd ed. North Sydney: Good Grief Ltd.

Good Grief (2012) Seasons for Healing Companion Manual. North Sydney: Good Grief Ltd. 
Good Grief (2013) Good Grief Ltd, Home page. North Sydney: Good Grief Ltd. Available: http://www.goodgrief.org.au

Guba, E. G. and Lincoln, Y. S. (1994) 'Competing Paradigms in Qualitative Research', in N. K. Denzin and Y. S. Lincoln (eds) Handbook of Qualitative Research, pp. 105-117. Thousand Oaks, CA: Sage Publications.

Gunaratnam, Y. (2003) Researching Race and Ethnicity: Methods, Knowledge and Power. London: Sage Publications.

Hollinsworth, D. (2012) 'Forget Cultural Competence; Ask for an Autobiography', Social Work Education: The International Journal. Epub ahead of print 12 December 2012. DOI:10.1080/02615479.2012.730513.

Ife, J. (2010) Human Rights from Below. Melbourne: Cambridge University Press.

Kovach, M. (2009) Indigenous Methodologies: Characteristics, conversations and contexts. Toronto: University of Toronto Press.

Madison, D. S. (2005) Critical Ethnography: Method, Ethics and Performance. Thousand Oaks, CA: Sage Publications.

Martin, K. L. (2003) 'Ways of Knowing, Ways of Being and Ways of Doing: a theoretical framework and methods for Indigenous re-search and Indigenist research', in K. McWilliam, P. Stephenson, and G. Thompson (eds) 'Voicing Dissent', New Talents 21C: Next Generation Australian Studies, 76: 203-214.

McQuiston, C., Choi-Hevel, S. and Clawson, M. (2001). Protegiendo Nuestra Comunidad: Empowerment Participatory Education for HIV Prevention. Journal of Transcultural Nursing, 12(4): 275-283.

Miller, K. (2014). Respectful listening and reflective communication from the heart and with the spirit. Qualitative Social Work, 13(6): 828-841.

Nakata, M. (2007) Disciplining the savages - Savaging the disciplines. Canberra, Aboriginal Studies Press.

Pelias, R. J. (2011) 'Writing into Position: Strategies for Composition and Evaluation', in N. K. Denzin and Y. S. Lincoln (eds) The Sage Handbook of Qualitative Research, 4th ed, pp. 659-668. Thousand Oaks, CA: Sage Publications.

Reason, P. (1988) 'Introduction', in P. Reason (ed) Human Inquiry in Action: Developments in New Paradigm Research, pp.1-17. London: Sage.

Safe Living in Aboriginal Communities Project, Whyalla (2002). Canberra: Commonwealth of Australia.

Shor, I. and Freire, P. (1987) A Pedagogy for Liberation: Dialogues on Transforming Education. South Hadley, MA: Begin \& Garvey.

Swantz, M. and Vainio-Mattila, A. (1988) 'Participatory Inquiry as an Instrument of GrassRoots Development', in P. Reason (ed) Human Inquiry in Action: Developments in New Paradigm Research, pp.127-143. London: Sage.

Tuhiwai Smith, L. (1999) Decolonizing Methodologies: Research and Indigenous Peoples. London: Zed Books.

Tuhiwai Smith, L. (2012) Decolonizing Methodologies: Research and Indigenous Peoples, 2nd ed. London: Zed Books.

Wallerstein, N. and Bernstein, E. (1994) Introduction to Community Empowerment, Participatory Education and Health. Health Education Quarterly, 21(2): 141-148.

Worden, J. W. (2009) Grief Counselling and Grief Therapy: A Handbook for the Mental Health Practitioner, 4th ed. New York: Springer Publishing Company. 